\title{
Ecotoxicology of Methylmercury: A Transdisciplinary Challenge
}

Many of us vividly recall the devastating effects of point source mercury $(\mathrm{Hg})$ pollution in Minimata Bay, Japan, documented by poignant photos of mothers caring for their children afflicted with crippling deformities. From 1952 to 1968 , Hg waste from the production of acetaldehyde and vinyl chloride was discharged (200-600 tons) into Minimata Bay. This resulted in $\mathrm{Hg}$ bioaccumulation by marine fish and shellfish, biomagnification in the marine food web, and subsequent ingestion by humans. Although this was perhaps the most severe case in history, the processes determining the fate of $\mathrm{Hg}$ in the environment are common to all aquatic ecosystems.

The Minimata catastrophe also revealed that the neurotoxicological effects on fetal development from pregnant women ingesting $\mathrm{Hg}$-contaminated fish could be especially severe. This finding, as well as research over subsequent decades on the processes of $\mathrm{Hg}$ bioaccumulation and biomagnification in aquatic and marine ecosystems, has led to today's warnings by many public health agencies about pregnant women limiting their consumption of fish like tuna, swordfish, shark, and other species that feed on the top of food chains.

Yet, as with most environmentally mediated health risks involving either chemical or biological agents, the ecological dimensions and health effects of $\mathrm{Hg}$ are far more subtle than either the tragic Minimata case or the health warnings suggest. This was illustrated more recently by pioneering transdisciplinary and participatory research carried out in Brazil to address chronic, lowlevel mercury exposure. These efforts demonstrated the efficacy of an "ecosystem approach" in revealing how deforestation and farming practices in the Amazon led to subclinical but nonetheless debilitating neurological manifestations-a "best practice" case example in ecohealth (Lebel 2003).

Few environmental health issues demand a transdisciplinary research agenda that spans such a wide range of disciplines-from biogeochemistry and ecosystem ecology to epidemiology and participatory action research-as environmental exposure to methylmercury ( $\mathrm{MeHg}$ ). Also, among the classic environmental health issues involving human and wildlife exposures to persistent and global contaminants (e.g., lead and organochlorides), $\mathrm{MeHg}$ remains the least resolved, in terms of both science and policy.

In the summer of 2006, the "Eighth International Conference on Mercury As a Global Pollutant" was held in Madison, Wisconsin, to which over 1000 scientists from around the world came to share their understanding of the environmental fate of this pervasive contaminant (Hurley et al. 2007). The global nature of $\mathrm{Hg}$ is due to a number of factors: (1) It is generated largely from coal-fired power plants which are increasing worldwide; (2) it is atmospherically transported from these sources to eventual deposition on all land and water surfaces; and (3) it is transferred to humans through fish consumption which knows no international or socioeconomic boundaries.

Since the fate, bioavailability, and toxicity of $\mathrm{Hg}$ and $\mathrm{MeHg}$ are controlled by physical, biogeochemical, and biological processes, the study of $\mathrm{Hg}$ is by necessity an interdisciplinary endeavor. $\mathrm{Hg}$ in the environment is found in several forms. In the atmosphere, it is predominantly elemental $\mathrm{Hg}\left(\mathrm{Hg}^{0}\right)$; in water, it is mostly the inorganic form $\mathrm{Hg}^{2+}$; and in aquatic sediments, it is transformed from $\mathrm{Hg}^{2+}$ into the more toxic organic form, $\mathrm{MeHg}$. $\mathrm{MeHg}$ is the form preferentially assimilated by living organisms and the dominant form found in fish that humans con- 
sume. Each of the environmental transformation steps is controlled by complex chemical and biological processes, as is the bioaccumulation and trophic transfer of $\mathrm{Hg}$ in aquatic food webs. As a result, the community of scientists who study $\mathrm{Hg}$ fate includes atmospheric scientists, biogeochemists, aquatic ecologists, wildlife ecologists, toxicologists, and epidemiologists.

At the $2006 \mathrm{Hg}$ meeting, there were many discussion and votes were tallied to assess the consensus on certain scientific conclusions. For example, $97 \%$ of scientists agreed that although there have been major reductions in $\mathrm{Hg}$ emissions in the US and Europe, there has been no change in the total Hg pool-likely due to the increase in emissions from other geographic areas (Anonymous 2007). Less agreed upon were issues related to $\mathrm{Hg}$ and human health; among them was the role of selenium in reducing Hg toxicity (69\% consensus; Anonymous 2007).

Although there are animal studies showing that selenite reduces inorganic $\mathrm{Hg}$ toxicity, there is almost no evidence for protection from $\mathrm{MeHg}$ toxicity by the organic forms of selenium found in the human diet. Moreover, there are no human studies for showing a protective role for selenium against $\mathrm{Hg}$ neurotoxicity (Mergler et al. 2007). Most agreed that this was an area of $\mathrm{Hg}$ research that requires a great deal more investigation.

The wide attendance of the $2006 \mathrm{Hg}$ conference was indeed a reflection of how much research had already been conducted on the fate and effects of Hg. But like all complex environmental problems, there remain many gaps in our knowledge. Since the main vector for human exposure is consumption of marine fish and shellfish, its fate in marine systems is particularly important to understand. Much of the past research has been conducted in freshwater and upland forested ecosystems, and, in many of the discussions by panels of scientists at the meeting, there was a recurring recognition that there needs to be greater focus on understanding $\mathrm{Hg}$ fate in marine ecosystems (Mergler et al. 2007; Munthe et al. 2007; Swain et al. 2007). Of the many unanswered questions, examples include: Where are the main sources of $\mathrm{Hg}$ methylation in the oceans that supply MeHg to the tuna fish that humans eat? Since MeHg is transferred mostly through food consumption, what are the predator-prey linkages in marine food webs that result in trophic transfer of $\mathrm{MeHg}$ ? Are coastal populations at greater risk of $\mathrm{Hg}$ exposure than inland populations?

These questions and others became the focus of a subsequent workshop sponsored by the National Institute of Environmental Health Science in the autumn of 2006 on
$\mathrm{Hg}$ fate and bioavailability in marine ecosystems (Chen et al. 2008). Scientists spanning a range of disciplines from biogeochemistry to biomedical sciences were convened and their discussions were the genesis of the $\mathrm{MeHg}$ articles found in this issue's Special Feature.

Without a doubt, the Hg problem is far from diminishing. $\mathrm{Hg}$ emissions and deposition are driven globally by growing energy demand and the increasing numbers of coal-fired power plants being constructed worldwide. Fisheries in all the world's oceans are impacted by this ubiquitous pollutant and indigenous populations reliant on fish or marine mammal species at the top of the food chain are at particular risk of exposure. Although the human impacts of the Minimata $\mathrm{Hg}$ poisonings were extremely acute and particularly disastrous, the more subtle effects of long-term chronic exposure to $\mathrm{MeHg}$ are far more common and widespread. The pervasiveness and complexity of this problem and its interaction with accelerating transformations and stresses on ecosystems (remove) worldwide, point to the need for much more research—especially employing transdisciplinary approaches that span marine chemistry, ecosystem ecology, wildlife health, and human physiology and development.

We are pleased to feature this Special Feature on $\mathrm{MeHg}$ and hope it will spur increased research interest and intervention to reduce the risk and impacts of $\mathrm{MeHg}$ toxicity on ecosystems, including humans.

\section{Celia Chen}

Department of Biological Sciences

Dartmouth College, Hanover, $\mathrm{NH}$

Bruce A. Wilcox

Asia-Pacific Institute for Tropical Medicine and Infectious Diseases

University of Hawaii, Honolulu, HI

e-mail: Celia.Y.Chen@Dartmouth.EDU.

\section{REFERENCE}

Anonymous (2007) The Madison declaration on mercury pollution. Ambio 36:62-65

Chen CY, Serrell N, Evers DC, Fleishman BJ, Lambert KF, Weiss J, et al. (2008) Methylmercury in marine ecosystems: from sources to seafood consumers-a workshop report. Environmental Health Perspectives; DOI:10.1289/ehp.1121.

Hurley JP, Krabbenhoft DP, Wiener JG, Babiarz CL (2007) Preface to the Madison declaration and critical synthesis papers on mercury pollution. Ambio $36: 2$ 
Lebel J (2003) Health: an ecosystem approach, Ottawa, Canada: International Development Research Centre

Mergler D, Anderson HA, Chan HM, Mahaffey KR, Murray M, Sakamoto M, et al. (2007) Methylmercury exposure and health effects in humans: a worldwide concern. Ambio 36:3-11

Munthe J, Bodaly R, Branfireun B, Driscoll C, Gilmour C, Harris $\mathrm{R}$, et al. (2007) Recovery of mercury-contaminated fisheries. Ambio 36:33-44
Swain E, Jakus P, Rice G, Lupi F, Maxson P, Pacyna J, et al. (2007) Socioeconomic consequences of mercury use and pollution. Ambio 36:45-61

Published online: March 6, 2009 